\title{
Homocysteine level in urine of autistic and healthy children
}

\author{
Joanna Kałużna-Czaplińska ${ }^{\bowtie}$, Monika Michalska and Jacek Rynkowski \\ Institute of General and Ecological Chemistry, Department of Chemistry, Technical University of Łódź, Łódź, Poland
}

\begin{abstract}
Homocysteine is an amino acid which plays several important roles in human physiology and is an important biomarker for possible deficiencies of various vitamins (vitamin $B_{6}$ and $B_{12}$, folic acid). In this work GC-MS method was used to determine the levels of homocysteine in the urine of autistic and healthy children. The levels of homocysteine in urine samples from 34 autistic and 21 healthy children were $2.36 \pm 1.24$ and $0.76 \pm 0.31$ (mmol. $\mathrm{mol}^{-1}$ creatinine), respectively. The higher level of homocysteine in autistic children may indicate deficiencies of folic acid and vitamins $B_{6}$ and $B_{12}$ in nutrition of these children. The results of this work were taken into consideration in the nutrition of autistic children treated in the Navicula Centre of Diagnosis and Therapy of Autism in Łódź (Poland).
\end{abstract}

Keywords: homocysteine, urine, GC/MS, autism

Received: 06 May, 2010; revised: 20 January, 2011; accepted: 24 January, 2011; available on-line: 11 March, 2011

\section{INTRODUCTION}

Autism is a complex metabolic disorder involving multiple organ systems, primarily immunological, gastrointestinal and neurological ones. Numerous factors causing autism have been proposed, among them nutrients, infections, genetic factors, and toxins (Chen et al., 2006). Nutrition plays an important role in the development and behavior of autistic children. Autistic people have a high prevalence of gastrointestinal diseases and dysbiosis (White, 2003). Amino acids eliminated with the urine, among them homocysteine, provide essential data about diet and the functioning of the alimentary system. Improper diet and poor condition of the alimentary system can have a strong influence on the enhancement of autism symptoms. In humans homocysteine is derived from methionine. Homocysteine is metabolised along two pathways: remethylation to methionine or transsulfuration to cysteine (Miller \& Kelly, 1996; Bald et al., 2000; Zinellu et al., 2007). A defect in either of these pathways leads to accumulation of homocysteine in the organism. Remethylation is a process which involves folic acid and vitamin $\mathrm{B}_{12}$. Transsulfuration involves vitamin $\mathrm{B}_{6}$. Thus, vitamins $B_{6}$ and $B_{12}$ and folic acid are necessary for lowering the level of homocysteine. Insufficient dietary intake of these nutrients can cause vitamin deficiencies which in turn can lead to increased homocysteine levels. Folic acid must be included in the diet because the organism cannot produce it (Surtees, 2001).

The main purpose of this study was to find out whether there are differences between the levels of homocysteine in the urine of autistic and healthy children. So far, the level of homocysteine has been determined in the serum and plasma of autistic children (James et al., 2004; Pasca et al., 2006).

For quantification of homocysteine, gas chromatography/mass spectrometry was used.

\section{MATERIAL AND METHODS}

Chemicals and material. Ethanol was purchased from J.T.Baker, pyridine from Chempur, ethyl chloroformate from Fluka, chloroform from Lab-Scan, octadecane (IS) from Fluka, homocysteine from ChromaDex.

Overnight urine samples were collected at 9 am once a week, for up to three consecutive months, from 34 autistic children (4-11 years) who underwent rehabilitation at the Navicula Centre of Diagnosis and Therapy of Autism in Lódź (Poland) and from 21 neurologically healthy children (4-11 years). Urine was stored at $-20^{\circ} \mathrm{C}$ until analysis. The children were diagnosed as autistic using the criteria for ICD-10 (DSM IV).

Daily intake of nutrients was evaluated on the basis of seven-day diet, described in a report prepared by the parents. Nutrient values, among others folic acid and vitamins $B_{6}$ and $B_{12}$, were calculated on the basis of literature data taking into account the portion size and dose of supplements (Kałużna-Czaplińska et al., 2009).

Standard and sample preparation. Homocysteine needs to be extracted from urine samples and next derivatized before the chromatographic analysis. In this method homocysteine was derivatized and extracted simultaneously. Ten microlitre octadecane $\left(100 \mu \mathrm{g} \cdot \mathrm{mL}^{-1}\right)$ was added as an internal standard to $0.5 \mathrm{~mL}$ urine sample which was then derivatized with $0.3 \mathrm{~mL}$ ethanol, $0.1 \mathrm{~mL}$ pyridine, $60 \mu \mathrm{L}$ ethyl chloroformate and 0.6 $\mathrm{mL}$ chloroform. Vials were placed on an orbital shaker at room temperature $\left(23 \pm 1^{\circ} \mathrm{C}\right)$ and shaken at $100 \mathrm{rpm}$ for $10 \mathrm{~min}$. The organic layer $(2 \mu \mathrm{L})$ was injected to gas chromatograph/mass spectrometer.

The samples were analyzed as soon as they were prepared. The analysis of a batch of about 30 samples was completed within about $8 \mathrm{~h}$.

Apparatus and chromatographic conditions. An Agilent Technology 6890 N Network GC System gas chromatograph with a 5973 Network Mass Selective mass spectrometer were used. Capillary column HP-5MS (30 $\mathrm{m} \times 0.25 \mathrm{~mm}$ i.d., film thickness $0.25 \mu \mathrm{m})$ was installed in the gas chromatograph and its output fed di-

\footnotetext{
e-mail: jkaluzna@p.lodz.pl

Abbreviations: GC/MS, gas chromatography/mass spectrometry; LC/MS, liquid chromatography/mass spectrometry; UV, ultraviolet; FD, fluorescence detector; MS/MS, tandem mass spectrometry; MS, mass spectrometry; DSM IV, Diagnostic and Statistical Manual of Mental Disorders; LOD, limit of detection; LOQ, limit of quantification; RSD, relative standard deviation; TIC, total ion chromatogram
} 
rectly into the ion source of the mass spectrometer. The oven temperature was programmed from $110^{\circ} \mathrm{C}(1 \mathrm{~min})$

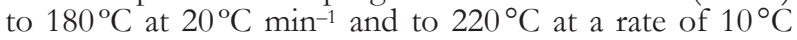
$\mathrm{min}^{-1}$. Injector temperature was $250^{\circ} \mathrm{C}$ and transfer line $280^{\circ} \mathrm{C}$. Helium was used as the carrier gas at a flow rate of $0.9 \mathrm{~mL} \cdot \mathrm{min}^{-1}$. To confirm the mass fragments of the derivatives, data were obtained in the full scan mode in the scan range from $\mathrm{m} / \mathrm{z} .50$ to 500 , and the selected masses $(\mathrm{m} / \mathrm{z})$ in the SIM (selected ion monitoring) mode for homocysteine were as follows: 56, 128, 234.

Creatinine concentration was determined chromatographically according to the procedure described in detail elsewhere (Kuśmierek et al., 2006).

Validation method. The method was validated for recovery, precision, limit of quantification (LOQ), limit of detection (LOD) and linearity.

Linearity. Stock solutions of homocysteine for calibration curves and validation procedures were prepared by dissolving appropriate amounts of the compound in $0.1 \mathrm{~mol} / \mathrm{L}^{-1}$ hydrochloric acid. The solutions were stored at $4{ }^{\circ} \mathrm{C}$. Homocysteine concentrations in urine and dilution linearity were assessed by using calibration curves. Calibration curves were established with various amounts of homocysteine and a constant amount of octadecane was added as an internal standard. Extraction and deri- vatization were performed following the sample preparation scheme described above.

Precision. Precision was evaluated by calculating the relative standard deviation (RSD) at four homocysteine dilutions: $0.5,1,2$ and $5\left(\mu \mathrm{g} \cdot \mathrm{mL}^{-1}\right)$. The intra-day precision values were determined in six replicates at each dilution, and these replicates were processed independently.

Sensitivity. The limit of detection (LOD) is defined as the lowest concentration of an analyte which can be readily detected, but not necessarily quantified. LOD was determined as the lowest concentration giving a signalto-noise ratio of 3 for homocysteine. The limit of quantification (LOQ) is defined as the lowest concentration of an analyte which can be quantified with acceptable precision and accuracy. LOQ was defined as the level giving a signal-to-noise ratio of 10 .

Recovery. Recovery was determined analysing urine samples to which known amounts of homocysteine $(0.2$ $\mu \mathrm{g} \cdot \mathrm{mL}^{-1}$ ) were added.

Statistical analysis. The statistical analysis of the results was carried out with the STATISTICA software programs version 9.0. The Shapiro-Wilk test was used to check for normal distribution of the data. The Mann-Whitney U test was used to compare mean values
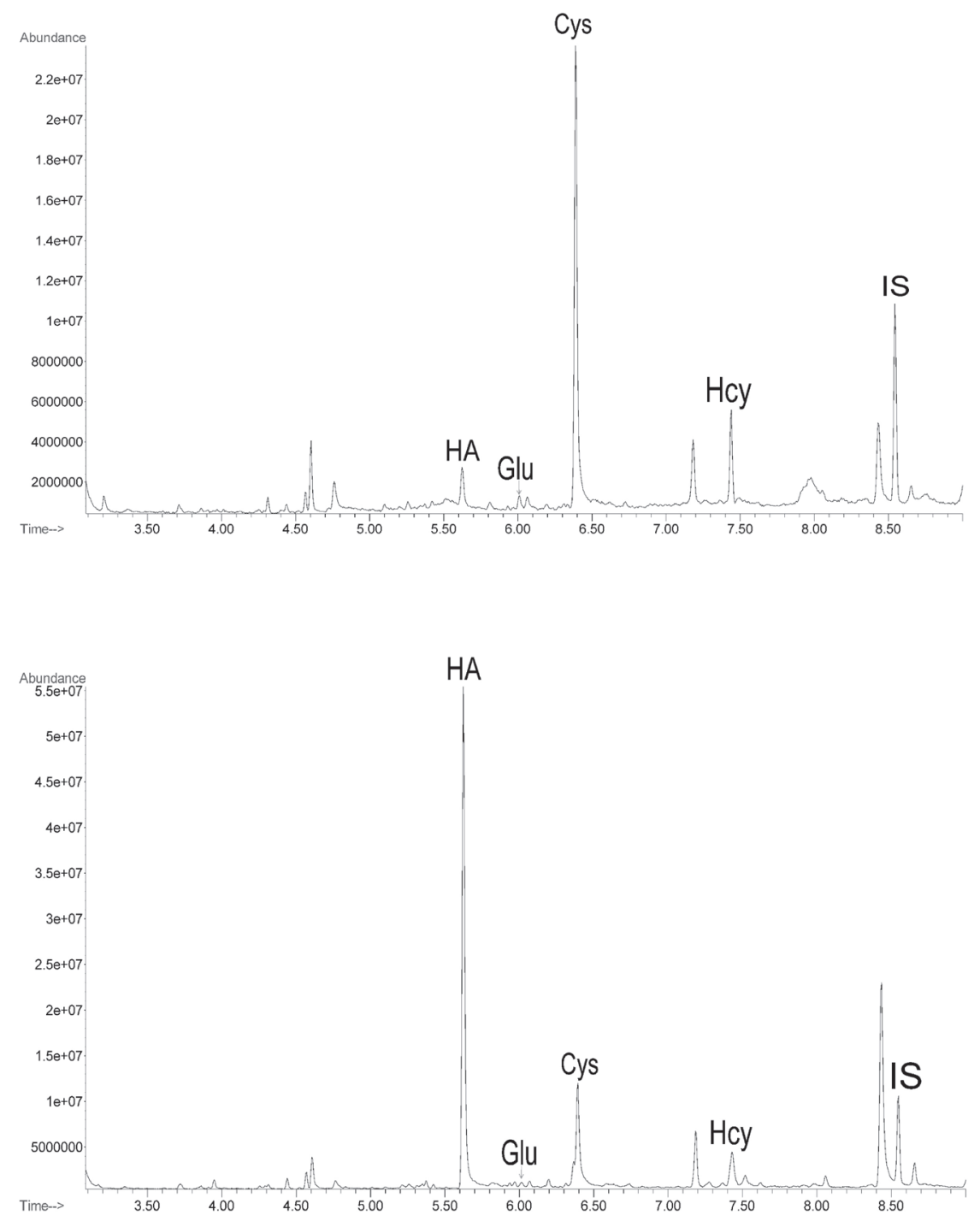

Figure 1. Scan mode total ion chromatogram (TIC) of the GC/MS analysis of urine

Top sample from autistic child, bottom sample from healthy child. Peaks: HA, hippuric acid; Glu, glutamic acid; Cys, cysteine; Hcy, homocysteine; IS, octadecane. Sample was prepared as described in Material and Methods. 
Table 1. Methods for determination of homocysteine in urine

\begin{tabular}{|c|c|c|c|c|c|c|}
\hline Technique & Detection & $\begin{array}{l}\text { Analysis time } \\
\text { (min) }\end{array}$ & $\begin{array}{l}\text { Sample volume } \\
(\mu \mathrm{L})\end{array}$ & $\begin{array}{l}\text { Recovery } \\
(\%)\end{array}$ & Correlation & Reference \\
\hline HPLC & UV & 12 & 1000 & $91-114$ & 0.9896 & (Kaniowska et al., 1998) \\
\hline HPLC & UV & 10 & 200 & $98.16-100.17$ & 0.9977 & (Kuśmierek et al., 2006) \\
\hline HPLC & FD & 9 & 10 & $96.5-99.3$ & 0.9977 & (Proksch et al., 2005) \\
\hline HPLC & FD & 7 & 10 & 102.0 & $>0.99$ & (Pastore et al., 1998) \\
\hline HPLC & FD & 1.9 & 75 & $95-105$ & 0.9994 & (Lochman et al., 2003) \\
\hline HPLC & MS/MS & 3 & 20 & $96.7-100.3$ & 0.9963 & (Rafii et al., 2007) \\
\hline GC & MS & 9 & 500 & 93 & 0.998 & (this paper) \\
\hline
\end{tabular}

for homocysteine in the autistic and non-autistic children. The level of statistical significance was defined as $P<0.05$.

\section{RESULTS AND DISCUSSION}

A typical, representative chromatograms (TIC-SCAN) of a urine sample from an autistic and a healthy child are shown in Fig. 1.

Homocysteine is most frequently analyzed by liquid chromatography (LC) or LC/mass spectrometry (LC/ MS). Examples of a number of procedures in use are given in Table 1. Generally they offer analysis time similar or shorter than does the GC/MS method used here and need lower sample volumes.

According to Myunga (1999) gas chromatographic assay methods have rarely been reported for homocysteine because of the incompatibility of thiols with the GC system. Homocysteine is highly polar due to its amine $\left(-\mathrm{NH}_{2}\right)$, carboxylic acid $(-\mathrm{COOH})$ and thiol $(-\mathrm{SH})$ groups and consequently can not be easily extracted from biological fluids using organic solvents. Derivatization is needed to increase its solubility in organic solvents and volatility for the GC chromatography. Several highly sensitive gas chromatography/mass spectrometry detection applications have been reported (Pietzsch et al., 1997; Ducros et al., 1999; Nekrassova et al., 2003).

In this study, the relative standard deviation (RSD) for $0.5,1,2$ and $5 \mu \mathrm{g} \cdot \mathrm{mL}^{-1}$ of homocysteine was 9.7, $9.4,8.9$ and $7.2(\%)$, respectively, and the RSD below $10 \%$ indicate reasonable derivatization efficiency and stability. The limit of detection (LOD) was $0.06 \mu \mathrm{g} \cdot \mathrm{mL}^{-1}$ and the limit of quantification (LOQ) was $0.20 \mu \mathrm{g} \cdot \mathrm{mL}^{-1}$. The calibration curve was linear over the range $0.2-5$ $\mu \mathrm{g} \cdot \mathrm{mL}^{-1}$ and the correlation coefficient was 0.998 . The analytical recovery was $93 \%$ (repetition number, $n=6$ ), which indicates a high reproducibility of the method.

Table 2. Concentrations of urinary homocysteine in autistic and healthy children (mean \pm S.D.)

\begin{tabular}{ll}
\hline Group & $\begin{array}{l}\text { Homocysteine } \\
(\text { mmol mol }\end{array}$ \\
\hline Autistic children $\mathrm{n}=34$ & $2.36 \pm 1.24$ \\
Healthy children $\mathrm{n}=21$ & $0.76 \pm 0.31$
\end{tabular}

To summarize, one can state that despite some advantages of HPLC methods, also those based on GC/MS can be successfully applied.

The mean values found for urinary homocysteine levels in the analyzed urine samples are listed in Table 2. The average level of homocysteine in the urine of 34 autistic children was $2.36 \pm 1.24$, and for the 21 control children $0.76 \pm 0.31\left(\mathrm{mmol} \cdot \mathrm{mol}^{-1}\right.$ creatinine). Homocysteine values did not show normal distribution. There are significant differences between urinary homocysteine values in autistic and control children $(P<0.05)$. The level of urinary homocysteine for autistic children is therefore significantly higher than that for healthy ones.

Monitoring of homocysteine in various body fluids may give an information about possible deficiencies of various vitamins: $\mathrm{B}_{6}, \mathrm{~B}_{12}$ and folic acid (Nekrassova et al., 2003). Refsum et al. (2004) discussed application of total homocysteine (tHcy) measurements in the diagnosis of folate and vitamin $\mathrm{B}_{12}$ deficiencies in various psychiatric and neurologic disorders. High levels of homocysteine and oxidative stress are generally associated with neuropsychiatric disorders, such as autism (Chauhan \& Chauhan, 2006; Suh et al., 2008).

James and coauthors (2004) indicated a generally decreased capacity for methylation, associated with low levels of plasma homocysteine in children with autism compared to controls. It was noticed that $80 \%$ of autistic children were taking folic acid (800 $\mu \mathrm{g}$ daily) and vitamin $B_{12}$ (injection of $75 \mu \mathrm{g}$ of the methylcobalamin/ $\mathrm{kg}$ ) supplements prior to the beginning of the study and such a treatment could have decreased the level of homocysteine. Therefore the level of homocysteine $\left(\mu \mathrm{mol} \cdot \mathrm{L}^{-1}\right)$ in the plasma of autistic and control children was found almost the same $(5.8 \pm 1.0$ and $6.4 \pm 1.3$, respectively).

On the other hand, according to Pasca et al. (2006) the levels of tHcy in serum were significantly higher in autistic children $\left(9.83 \pm 2.75 \mu \mathrm{mol} \cdot \mathrm{L}^{-1}\right)$ compared to a control group of healthy children $\left(7.51 \pm 0.93 \mu \mathrm{mol} \cdot \mathrm{L}^{-1}\right)$. The $\mathrm{B}_{12}$ vitamin levels $\left(368.16 \pm 154.64 \mathrm{pmol} \cdot \mathrm{mL}^{-1}\right)$, assayed only in the autistic group, were found to be suboptimal for seven children (of a total of 12) and lower for a further two of them compared to the age-matched reference ranges (nine children). The result of Pasca and coworkers are consistent with other observations of autistic children (Boris et al., 2004; Waly et al., 2004; Moretti et al., 2005). These observations suggest that hyperhomocysteinemia might be present in autism. 
Our earlier research suggested that many autistic children had vitamin deficiencies caused by improper diets (Kałużna-Czaplińska et al., 2009). In the case of autistic children a specific diet is of great importance. Many children with autism spectrum disorders display substantial food selectivity (Ahearn et al., 2001; Williams et al., 2005; Paul et al., 2007). The reasons for the too high concentration of homocysteine in their organisms are nutrientrelated deficiencies of folic acid, vitamin $B_{12}$, or vitamin $\mathrm{B}_{6}$ resulting in aggravation of some autistic symptoms.

This work shows that a higher level of homocysteine in the urine can be used as a marker of possible nutritional deficits. This relatively simple assay makes it easier to control the nutrition of autistic children. Its crucial advantage is that it does not require invasive procedures, such as those for plasma/serum collection, that are particularly stressful for autistic patients.

The results of this work were taken into consideration in adjusting the nutrition of autistic children treated at the Navicula Centre of Diagnosis and Therapy of Autism in Lódź (Poland) with a promising effect.

\section{Acknowledgements}

Supported by grant NN 204316234 from the Ministry of Science and Higher Eduction.

We would like to thank Dr. A. Szymańska and the parents of the autistic children from the Navicula Centre of Diagnosis and Therapy of Autism in Lódź (Poland) for their help in collecting urine samples.

\section{REFERENCES}

Ahearn WH, Castine T, Nault K, Green G (2001) An assessment of food acceptance in children with autism or pervasive developmental disorder - not otherwise specified. J Autism Dev Disord 31: 505511.

Bald E, Kaniowska E, Chwatko G, Głowacki R (2000) Liquid chromatographic assessment of total and protein-bound homocysteine in human plasma. Talanta 50: 1233-1243.

Boris M, Goldblatt A, Galanko J, James JM (2004) Association of MTHFR gene variants with autism. I Am Phys Surg 1: 106-108.

Chen H, Chen Y, Horn R, Yang Z, Wang C, Turner MJ, Zhang K (2006) Clinical features of autosomal dominant retinitis pigmentosa associated with a rhodopsin mutation. Ann Acad Med Singapore 35: 411-415.

Chauhan A, Chauhan V (2006) Oxidative stress in autism. Pathophysiology 13: 171-181.

Ducros V, Schmitt D, Pernod G, Faure H, Polack B, Favier A (1999) Gas chromatographic-mass spectrometric determination of total homocysteine in human plasma by stable isotope dilution: method and clinical applications. J Chromatogr B 729: 333-339.

James SJ, Cutler P, Melnyk S, Jernigan S, Janak L, Gaylor DW, Neubrander JA (2004) Metabolic biomarkers of increased oxidative stress and impaired methylation capacity in children with autism $\mathrm{Am}$ J Clin Nutr 80: 1611-1617.

Kałużna-Czaplińska J, Michalska M, Socha E, Błaszczyk S, RozettiSzymańska A, Rynkowski J (2009) Nutritional deficiencies in children for example of autistic children. Nowa Pediatria 4: 94-100 (in Polish).

Kaniowska E, Chwatko G, Głowacki R, Kubalczyk P, Bald E (1998) Urinary excretion measurement of cysteine andhomocysteine in the form of their S-pyridinium derivatives by high-performance liquid chromatography with ultraviolet detection. I Chromatogr A 798: 2735.

Kuśmierek K, Głowacki R, Bald E (2006) Analysis of urine for cysteine, cysteinylglycine, and homocysteine by high-performance liquid chromatography. Anal Bioanal Chem 385: 855-860.

Lochman P, Adam T, Friedecky D, Hlidkova E, Skopkova Z (2003) High-throughput capillary electrophoretic method for determination oftotal aminothiols in plasma and urine. Electrophoresis 24: 12001207.

Miller AM, Kelly GS (1996) Methionine and homocysteine metabolism and the nutritional prevention of certain birth defects and complications of pregnancy. Altern Med Rev 4: 220-235.

Moretti P, Sahoo T, Hyland K, Bottiglieri T, Peters S, del Gaudio D, Roa B, Curry S, Zhu H, Finnell RH, Neul JL, Ramaekers VT, Blau N, Bacino CA, Miller G, Scaglia F (2005) Cerebral folate deficiency with developmental delay, autism, and response to folinic acid. Neurology 6: 1088-1090.

Nekrassova O, Lawrence NS, Compton RG (2003) Analytical determination of homocysteine: a review. Talanta 6: 1085-1095.

Pasca SP, Nemes B, Vlase L, Gagyi CE, Dronca E, Miu AC and Dronca M (2006) High levels of homocysteine and low serumparaoxonase 1 arylesterase activity in children with autism. Life Science 78: $2244-2248$.

Pastore A, Massoud R, Motti C, Lo Russo A, Fucci G, Cortese C, Federici G (1998) Fully automated assay for total homocysteine, cysteine, cysteinylglycine, glutathione, cysteamine, and 2-mercaptopropionylglycine in plasma and urine. Clin Chem 44: 825-832.

Paul C, Williams KE, Riegel K, Gibbons B (2007) Combining repeated taste exposure and escape prevention: an intervention for the treatment of extreme food selectivity. Appetite 49: 708-711.

Pietzsch J, Julius U, Hanefeld M (1997) Rapid determination of total homocysteine in human plasma by using $N(O, S)$-ethoxycarbonyl ethyl ester derivatives and gas chromatography-mass spectrometry. Clin Chem 43: 2001-2004.

Proksch B, Jelesnianski S, Oberrauch W, Fuxa R, Gleiter Ch (2005) Adaptation of a high-performance liquid chromatographic method for quantitative determination of homocysteine in urine. J Chromatogr B 828: 122-125.

Rafii M, Elango R, Courtney-Martin G, House JD, Fisher L, Pencharz PB (2007) High-throughput and simultaneous measurement of homocysteine and cysteine in human plasma and urine by liquid chromatography-electrospray tandem mass spectrometry. Anal Biochem 371: 71-81.

Refsum H, Smith AD, Ueland PM, Nexo E, Clarke R, McPartlin J, Johnston C, Engbaek F, Schneede J, McPartlin C, Scott JM (2004) Facts and recommendations about total homocysteine determinations: an expert opinion. Clin Chem 50: 3-32.

Suh JH, Walsh WJ, McGinnis WR, Lewis A, Ames BN (2008) Altered sulfur amino acid metabolism in immune cells of children diagnosed with autism. Am J Biochem Biotech 4: 105-113.

Surtees R (2001) Cobalaminand folate responsive disorders. Baxter P, ed, pp 96-98. Mac Keith Press, London.

Waly M, Olteanu H, Banerjee R, Choi SW, Mason JB, Parker BS, Sukumar S, Shim S, Sharma A, Benzecry JM, Power-Charnitsky VA, Deth RC (2004) Activation of methionine synthase by insulin-like growth factor-1 and dopamine: a target for neurodevelopmental toxins and thimerosal. Mol Psychiatry 9: 358-370.

White JF (2003) Intestinal pathophysiology in autism. Exp Biol Med 228: 639-649.

Williams KE, Gibbons BG, Schreck KA (2005) Food comparing selective eaters with and without developmental disabilities. J Dev Phys Disabil 17: 299-309.

Zinellu A, Sotgia S, Usai MF, Zinellu E, Posadino AM, Gaspa L, Chessa R, Pinna A, Carta F, Deiana L, Carru C (2007) Plasma methionine determination by capillary electrophoresis-UV assay: application on patients affected by retinal venous occlusive disease. Anal Biochem 363: 91-96. 